\title{
Course of cognitive functioning during stroke rehabilitation
}

Citation for published version (APA):

Rasquin, S. M. C., Welter, J., \& van Heugten, C. M. (2013). Course of cognitive functioning during stroke rehabilitation. Neuropsychological Rehabilitation, 23(6), 811-823.

https://doi.org/10.1080/09602011.2013.821950

Document status and date:

Published: 01/12/2013

DOI:

10.1080/09602011.2013.821950

Document Version:

Publisher's PDF, also known as Version of record

Document license:

Taverne

Please check the document version of this publication:

- A submitted manuscript is the version of the article upon submission and before peer-review. There can be important differences between the submitted version and the official published version of record.

People interested in the research are advised to contact the author for the final version of the publication, or visit the DOI to the publisher's website.

- The final author version and the galley proof are versions of the publication after peer review.

- The final published version features the final layout of the paper including the volume, issue and page numbers.

Link to publication

\footnotetext{
General rights rights.

- You may freely distribute the URL identifying the publication in the public portal. please follow below link for the End User Agreement:

www.umlib.nl/taverne-license

Take down policy

If you believe that this document breaches copyright please contact us at:

repository@maastrichtuniversity.nl

providing details and we will investigate your claim.
}

Copyright and moral rights for the publications made accessible in the public portal are retained by the authors and/or other copyright owners and it is a condition of accessing publications that users recognise and abide by the legal requirements associated with these

- Users may download and print one copy of any publication from the public portal for the purpose of private study or research.

- You may not further distribute the material or use it for any profit-making activity or commercial gain

If the publication is distributed under the terms of Article $25 \mathrm{fa}$ of the Dutch Copyright Act, indicated by the "Taverne" license above, 


\section{Course of cognitive functioning during stroke rehabilitation}

\section{S. M. C. Rasquin, J. Welter \& C. M. van Heugten}

To cite this article: S. M. C. Rasquin, J. Welter \& C. M. van Heugten (2013) Course of cognitive functioning during stroke rehabilitation, Neuropsychological Rehabilitation, 23:6, 811-823, DOI: 10.1080/09602011.2013.821950

To link to this article: https://doi.org/10.1080/09602011.2013.821950

曲 Published online: 02 Sep 2013.

Submit your article to this journal

Llll Article views: 772

Q View related articles $₫$

4 Citing articles: 3 View citing articles 


\title{
Course of cognitive functioning during stroke rehabilitation
}

\author{
S. M. C. Rasquin ${ }^{1,2}$, J. Welter ${ }^{1}$, and C. M. van Heugten ${ }^{3}$ \\ ${ }^{1}$ Adelante Rehabilitation Foundation, Hoensbroek, Limburg, \\ The Netherlands \\ ${ }^{2}$ Department of Rehabilitation, University Medical Centre, CAPHRI, \\ Maastricht, The Netherlands \\ ${ }^{3}$ School for Mental Health and Neuroscience, Faculty of Health, Medicine \\ and Life Sciences; Department of Neuropsychology and \\ Psychopharmacology, Faculty of Psychology and Neuroscience, Maastricht \\ University, Maastricht, The Netherlands
}

(Received 22 October 2012; accepted 28 June 2013)

The aim of the study was to determine the course of cognitive functioning within the subacute phase ( $<4$ months) after stroke during rehabilitation. Stroke patients admitted to a rehabilitation centre were submitted to a neuropsychological examination on admission (1 month post-stroke) and upon discharge (4 months post-stroke). Cognitive domains studied were attention, executive functioning, memory, and visual attention. Forty-two patients (mean age $=57.1$ years; $S D=7.7$ ) participated. At admission more than half of the patients showed deficits in attention and memory. Patients improved significantly on these domains; the largest improvement was seen in the domain of visual attention, while executive functioning did not improve significantly. A differential course of cognitive functioning was found in the subacute phase after stroke. The prognosis of visual attention is the most prominent.

Keywords: Cognition; Stroke; Course; Rehabilitation; Neuropsychological functioning.

Correspondence should be addressed to S. Rasquin $\mathrm{PhD}$, Rehabilitation Foundation Limburg, PO Box 88 /6430 AB Hoensbroek, The Netherlands. E-mail: s.rasquin@ adelante-zorggroep.nl

(C) 2013 Taylor \& Francis 


\section{INTRODUCTION}

In The Netherlands approximately 190,000 individuals live with the aftermath of a stroke, with an estimated annual increase of 41,000 patients (Bots \& van Dis, 2006). The most well-known and thoroughly investigated impairments caused by a stroke are those of a physical nature. However, over the last few decades, attention has shifted towards the less visible cognitive impairments which are common in more than half of stroke survivors, and can have a negative influence on daily life functioning, rehabilitation outcome and quality of life (van der Zwaluw, Valentijn, NieuwenhuijsMark, Rasquin, \& van Heugten, 2011)

Longitudinal studies on cognitive deficits after stroke have followed patients with intervals of six months (Rasquin et al., 2004; Nys et al., 2005) or 1 year (Wagle et al., 2011). These studies showed that improvement in cognitive functioning is possible, mainly within the first six months, but in many patients cognitive deficits remain present. No information is, however, available on the course of cognitive functioning within the first few months after stroke when the brain is primed to neurological recovery in response to rehabilitation (Taesell, Bitensky, Salter, \& Bayona, 2005). Early and intensive training has been shown to be effective in arm function (Wolfe et al., 2006) and language (Berthier \& Pulvermüller, 2011), but what about cognitive functions? This question cannot be answered on the basis of the current evidence. A study on cognitive recovery early after stroke is therefore urgently needed.

Most of the studies investigating course of cognitive functioning after stroke assessed specific cognitive domains, making comparison between different cognitive functions difficult. Little has been mentioned about the differential course comparing one cognitive domain to another. This illustrates the difficulty of ascertaining a clear pattern of the course of these cognitive functions. Christensen et al. (2008) studied recovery patterns of cognitive function in the first year after traumatic brain injury. They specifically investigated differential recovery across cognitive domains and showed that recovery is not uniform. Recovery trajectories varied as a function of cognitive domain in the first 5 months, but not in the period from month 5 to 12 after injury. Such information is not available for stroke patients.

Another problem arises when attempting to understand the course of cognitive functioning in the subacute phase after stroke by using global instruments, mainly developed for detecting dementia, such as the Mini Mental State Examination (MMSE; Folstein, Folstein, \& McHugh, 1975). These tests are not equipped to differentiate between separate cognitive domains or to detect subtle cognitive changes.

In sum, more research on cognitive functioning early after stroke is needed to facilitate a better understanding and to shape allocation of rehabilitation 
resources (Hochstenbach, Donders, Mulder, van Limbeek, \& Schoonderwaldt, 1996). Considering most cognitive changes occur within the first six months after a stroke, the present study explored the course of cognitive functioning in four cognitive domains in stroke patients from admission to discharge from a rehabilitation centre situated in The Netherlands.

\section{METHODS}

\section{Subjects}

Patients eligible for the study were admitted to the Rehabilitation Centre Adelante, located in Hoensbroek, The Netherlands, in the period from July to December 2009. Inclusion criteria were: (1) stroke patients admitted to the rehabilitation centre Adelante, who received inpatient and outpatient rehabilitation treatment; (2) understanding of the Dutch language evaluated by a speech-therapist; and (3) age of $\leq 75$ years. Exclusion criteria were: (1) patients with aphasia for whom testing was not possible, and (2) patients with other neurological or psychiatric disorders for which treatment was necessary in the past 5 years (e.g., a tumour or major depression).

\section{Instruments}

The neuropsychological examination consisted of the following tests with proven validity and reliability for stroke patients: the Trail Making Test (attention), the Tower of London task (executive functioning), the Rivermead Behavioural Memory Test (memory), the Baking Tray Task and the O-search task (visual attention).

Trail Making Test (TMT). Both the original and the renewed version of the TMT were used to assess attention. The first half of the patients were submitted to the old version and the other half were submitted to the new version of the TMT. The original version has two parts (part A and part B). In part A the task requires the subject to connect the given digits in consecutive order. In part B the subjects are required to alternate between digits and letters.

The objective of the task is to finish as fast as possible and the time taken is measured (Reitan, 1956).

The new version retains the same purpose but has three additional conditions: visual scanning by letter cancellation, letter ranking and motor speed (Delis, Kaplan, \& Kramer, 2001). Part A and condition 2, respectively, were used to assess attention. For the old version of the TMT, no maximum time is set to complete the task, conversely a maximum time is set in the new version (2nd condition sets a maximum of 150 seconds, 4th condition sets a 
maximum of 240 seconds). Both the old and the new version of the TMT have standardised manuals to interpret the test score, and both tests are influenced by practice effects (Mitchel \& Miller, 2008).

Tower of London Task (TLT). Executive functioning, especially planning ability, was evaluated by the TLT. The purpose of this task is to investigate planning disorders. Patients receive three coloured blocks with which they have to make a plan to copy a given image. Patients have to use a mental strategy to imitate the given picture of a sequence, which taps into the planning ability. For every condition the patient has to imitate the picture within a certain amount of moves (2, 3, 4 or 5 moves). The patient is given three chances for each picture. Completion in one try scores 3 points; completion in two, 2 points; completion in three, 1 point, and no completion, 0 points. There are 12 pictures and the maximum score is 36 points. A score of $\leq 26$ is interpreted as impaired executive functioning/planning behaviour (Krikorian, Bartok, \& Gay, 1994). Healthy people perform better a second time on this test (Lemay, Bedard, Rouleau, \& Tremblay, 2004).

Rivermead Behavioural Memory Test (RBMT). For assessing disorders in everyday memory functioning we used the RBMT developed by Wilson, Cockburn, and Baddeley (1985) and translated into Dutch by Van Balen and Groot Zwaaftink (1987). The RBMT has several subtests which measure immediate and delayed memory and recognition. They are based upon real and reported everyday memory problems in patients with brain injury. The subtests include tasks with remembering a name and surname, a personal affect, an appointment, several pictures, a given story (immediate and delayed), faces, a given route (immediate and delayed), a message (immediate and delayed), the date, and orientation. The test has four parallel forms (A, B, C, and D) to avoid practice effects. We used version A (first assessment) and B (second assessment). There are two scoring systems: a screening and profile score. For the screening score, every item is scored 1 (true) or 0 (false) points. For the profile score every subtest is scored 2 (true), 1 (partly true), or 0 (false) points. The maximum screening score that can be obtained is 12 points and the maximum profile score that can be obtained is 24 points. In this study the profile score was used for its more detailed scoring system. Impairment for everyday memory is set at $<19$ points (Wilson et al., 1985).

$O$-search task. Visual attention was tested by the O-search task. This task measures the use of the visual space and the working method of visual scanning (Rasquin, Ooms, van de Sande, Beers, \& Schmand, 2009). The patient is asked to encircle the "O"s visible on a piece of A4 paper. Among these "O"s there are several other letters which have to be ignored. The cut-off point for 
neglect is $>6$ left-sided omissions. There are no practice effects (Rasquin et al., 2009).

Baking Tray Task. Visual attention was also tested with the Baking Tray Task (Tham \& Tegner,1996). The patient is seated in front of a large tray on which 16 blocks are situated. The blocks are aligned in a vertical manner in the centre of the tray. Patients are instructed to divide them equally along the table "as if baking rolls in the oven which are not allowed to stick together". The cut-off point for neglect is $\leq 6$ blocks positioned at the left side of the tray (Tham \& Tegner, 1996). There are no practice effects (Bailey, Riddoch, \& Crome, 2000).

Additionally, to evaluate functional dependency the Barthel index was used on admission and upon discharge (Wade \& Collin, 1998). The Barthel index is scored within a range of 0 (functionally dependent) to 20 (functionally independent). A score of 0-9 indicates severe dependency, 10-19 moderate dependency, and 20 full independence (de Haan et al., 1993).

\section{Rehabilitation regimes}

All patients were admitted to the rehabilitation centre. The type of rehabilitation regimes offered to the patients depended on their level of functioning. The frequency and intensity of psychotherapy, occupational therapy, and interventions by a social worker are comparable for all patients. Speech therapy is minimal in this patient population (speech therapy is only offered for dysarthria). Cognitive rehabilitation and psychological interventions depended on the needs of the patient and varied between 1 and 3 hours per week. Cognitive rehabilitation was either specific, such as practising clock-reading, or more generalised, such as learning new cognitive strategies.

\section{Procedure}

After admission to the rehabilitation centre all stroke patients are assessed as part of the standard diagnostic procedure including a standardised cognitive screening as described under instruments. Assessment is performed by a psychological assistant in a quiet room for testing; tests are always administered in the same order. For the purpose of this study, cognitive screening was repeated in the weeks before discharge (historically, patients were re-assessed at discharge, but before the start of the study this was not standard practice). All patients included in this study were re-assessed and there was no attrition. The patients in this study received a first cognitive screening within three weeks of admission which equates to approximately five weeks after stroke (mean days after stroke $=45.5, S D=18.6$ ). The second screening was administered approximately four months after the first screening (mean days $=$ 122.8, $S D=44.2$ ) and as close to discharge as possible. 
Information regarding age, gender, education, cognitive training, time interval between stroke and the first neuropsychological screening, time interval between the first and second screening, location and type of stroke was gathered from the medical records. The Barthel Index was scored by the nursing staff of the stroke department on admission and on discharge as part of regular care.

Informed consent was given and the procedure was approved by the local medical ethics committee.

\section{Data analysis}

Descriptive analyses were conducted to determine patient characteristics. Cognitive impairment at admission and discharge in a specific cognitive domain was measured by standardised scores falling below the $10^{\text {th }}$ percentile corrected norms. Furthermore, Chi-square analyses were performed for nominal and interval variables to assess group differences and MannWhitney $U$ tests for measuring group differences of continuous variables.

A distinction was made between cognitive functioning at test and domain level. Cognitive functioning at test level was analysed using raw test scores upon admission and upon discharge for each neuropsychological test administered. Cognitive functioning within the different cognitive domains was analysed using standardised test scores. The raw test scores were converted based upon mean and standard deviation of a reference group. Norm data of stroke patients' partners, gathered within the same rehabilitation centre, were used in the present study (van Heugten, Huygelen, \& van de Sande, 2004). Use of these standardised scores enables us to compare the different cognitive domains with each other. The domain "attention" was based on TMT scores (first part), "executive functioning" on the TLT scores, and "memory" on the RBMT scores. For "visual attention", no norm data were available for the Baking Tray Task; therefore only performance on the O-search task was used to determine recovery in this domain. For "attention", a compound score was calculated for both the old and new version of the TMT by averaging the standardised scores.

When more time is needed to complete a task (higher number of seconds), this is comparable to a lower score on the other tasks (lower number of correct responses). To make visual comparisons between the course of the cognitive domains in the graph possible, we converted timed tasks to negative scores.

All analyses were based on within-patient differences (the difference between assessment 1 and assessment 2).

As the course of cognitive functioning can be interfered by age, level of education, localisation of stroke, and cognitive rehabilitation, we corrected for these variables in linear regression analyses. Dependent variable is the amount of change in a specific cognitive domain (i.e., domain scores). 
Independent variables were stroke location (left-right-both), age, level of education (low-middle-high), and cognitive rehabilitation (yes/no). Multicollinearity was checked for, using the variance inflation factor (VIF) within the regression analysis. Mutlicollinearity was defined when the largest VIF was higher than 10, or the average VIF was greater then 1.

Statistical analyses were performed with the statistical package SPSS 15.0 for Windows. Alpha was set at .05 (two-tailed where applicable) for analyses of the cognitive recovery pattern. As this study is considered an exploratory study we did not correct for multiple comparisons.

\section{RESULTS}

\section{Patient characteristics}

Forty-two stroke patients referred to the stroke rehabilitation department were included in this study (mean age $=57.1$ years; 26 men and 16 women). Demographics and stroke-related data are presented in Table 1. All patients for whom a Barthel Index score was available at admission were moderately or severely disabled; at discharge $70 \%$ of the patients were moderately disabled (see Table 2).

TABLE 1

Baseline patient characteristics $(n=42)$

Demographics and stroke-related data

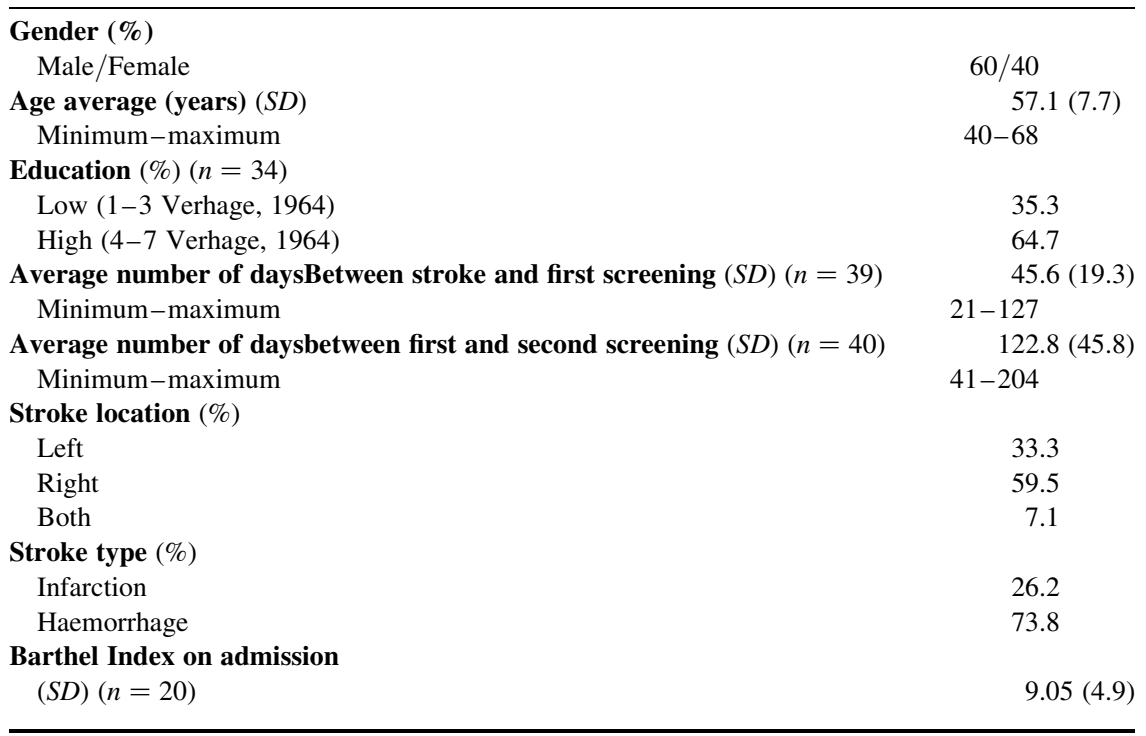


TABLE 2

Average raw test scores upon admission and discharge $(n=42)$

\begin{tabular}{|c|c|c|c|c|c|}
\hline & Baseline & & $\begin{array}{l}\text { Follow- } \\
\text { up }\end{array}$ & & \\
\hline & $\begin{array}{c}\text { Mean } \\
(S D)\end{array}$ & $\begin{array}{c}\% \text { Impaired } \\
(n)\end{array}$ & $\begin{array}{c}\text { Mean } \\
(S D)\end{array}$ & $\begin{array}{l}\% \text { Impaired } \\
(n)\end{array}$ & $\begin{array}{c}p \\
\text { value* }^{*}\end{array}$ \\
\hline \multicolumn{6}{|l|}{$\begin{array}{l}\text { Trail Making Task } \\
\quad(\text { old; } n=17)\end{array}$} \\
\hline Part A time (sec.) & $\begin{array}{c}88.6 \\
(64.9)\end{array}$ & $61.1 \%$ & $\begin{array}{l}71.8 \\
(52.4)\end{array}$ & $44.4 \%$ & $<.05$ \\
\hline Part B time (sec.) & $\begin{array}{l}200.8 \\
(133.6)\end{array}$ & & $\begin{array}{l}148.7 \\
(89.8)\end{array}$ & (8) & .111 \\
\hline Number of errors & $2.7(4.4)$ & $58.8 \%(10)$ & $1.8(3.3)$ & $52.9 \%(9)$ & .170 \\
\hline \multicolumn{6}{|l|}{$\begin{array}{l}\text { Trail Making Task } \\
\quad(\text { new; } n=19)\end{array}$} \\
\hline $\begin{array}{l}\text { Condition } 2 \text { time } \\
\text { (sec.) }\end{array}$ & $\begin{array}{c}73.6 \\
(34.0)\end{array}$ & $66.7 \%(12)$ & $\begin{array}{c}60.8 \\
(23.5)\end{array}$ & $44.4 \%(8)$ & .066 \\
\hline $\begin{array}{l}\text { Condition } 4 \text { time } \\
\text { (sec.) } \\
\text { number of errors }\end{array}$ & $\begin{array}{l}180.7 \\
(54.1)\end{array}$ & $77.8 \%(14)$ & $\begin{array}{l}164.5 \\
(61.9)\end{array}$ & $61.6 \%$ & .112 \\
\hline & $5.4(8.2)$ & & $3.4(6.2)$ & (11) & .337 \\
\hline \multicolumn{6}{|l|}{$\begin{array}{l}\text { Tower of London } \\
\quad(n=38)\end{array}$} \\
\hline Total score & $28.1(4.5)$ & $28.9 \%(11)$ & $\begin{array}{l}29.5 \\
(3.7)\end{array}$ & $18.4 \%(7)$ & .105 \\
\hline Time (sec.) & $\begin{array}{l}370.6 \\
(124.3)\end{array}$ & & $\begin{array}{c}360.5 \\
(125.3)\end{array}$ & & .693 \\
\hline \multicolumn{6}{|l|}{$\begin{array}{l}\text { Rivermead } \\
\text { Behavioural } \\
\text { Memory Task } \\
(n=40)\end{array}$} \\
\hline Profile score & $16.8(4.3)$ & $57.5 \%(23)$ & $\begin{array}{l}18.4 \\
(3.9)\end{array}$ & $45 \%(18)$ & $<.05$ \\
\hline Immediate recall & $6.9(3.7)$ & & $8.3(3.4)$ & & $<.05$ \\
\hline Delayed recall & $5.5(3.6)$ & & $7.6(3.8)$ & & $<.01$ \\
\hline \multicolumn{6}{|l|}{$O-\operatorname{search}(n=42)$} \\
\hline $\begin{array}{l}\text { Left-sided } \\
\text { omissions }\end{array}$ & $5.1(6.7)$ & $31 \%(13)$ & $1.5(2.7)$ & $14.3 \%(6)$ & $<.01$ \\
\hline $\begin{array}{l}\text { Right-sided } \\
\text { omissions }\end{array}$ & $2.1(3.9)$ & & $0.9(2.2)$ & & .106 \\
\hline Total time (sec.) & $\begin{array}{l}180.3 \\
(94.9)\end{array}$ & & $\begin{array}{l}198.2 \\
(95.8)\end{array}$ & & .313 \\
\hline Control time (sec.) & $\begin{array}{c}32.5 \\
(74.2)\end{array}$ & & $\begin{array}{c}42.1 \\
(59.5)\end{array}$ & & .472 \\
\hline \multicolumn{6}{|l|}{$\begin{array}{l}\text { Baking Tray Test } \\
(n=38)\end{array}$} \\
\hline $\begin{array}{l}\text { Number of cubes } \\
\text { left side }\end{array}$ & $6.6(3.0)$ & $31.6 \%(12)$ & $8.0(2.8)$ & $21.1 \%(8)$ & $<.05$ \\
\hline
\end{tabular}


TABLE 2.

Continued.

\begin{tabular}{lccccc}
\hline & Baseline & \multicolumn{3}{c}{ Follow- } \\
up & \\
\hline $\begin{array}{l}\text { Number of cubes } \\
\text { right side }\end{array}$ & $9.4(3.0)$ & & $7.9(2.8)$ & & $<.05$ \\
$\begin{array}{l}\text { Barthel index }(\boldsymbol{n}= \\
\text { 20) }\end{array}$ & $9.05(4.9)$ & $\begin{array}{c}\text { Severely65\% } \\
\text { (13)Moderately35\% (7) }\end{array}$ & $\begin{array}{l}17.2 \\
\text { (3.3) }\end{array}$ & $\begin{array}{c}\text { Severely5\% (1) } \\
\text { Moderately 70\% } \\
(14)\end{array}$ & $<. \mathbf{0 1}$ \\
\hline
\end{tabular}

$p<.05: *$ difference between mean test scores.

\section{Cognitive functioning at test level}

Table 2 presents cognitive functioning at admission and discharge for each test separately, and the differences between the two assessments.

Upon admission, more than half of the patients showed deficits on all scores of the TMT and on the profile score of the RBMT. Patients improved significantly on the TMT part A (old version), RBMT (profile score, immediate recall and delayed recall), O-search test (number of left-sided omissions) and Baking Tray Task (number of cubes left side and right side) after rehabilitation.

\section{Cognitive functioning within a cognitive domain}

The highest percentage of cognitive deficits was found in the domains visual attention and attention, both at admission (61.9\% and $62.2 \%$, respectively)

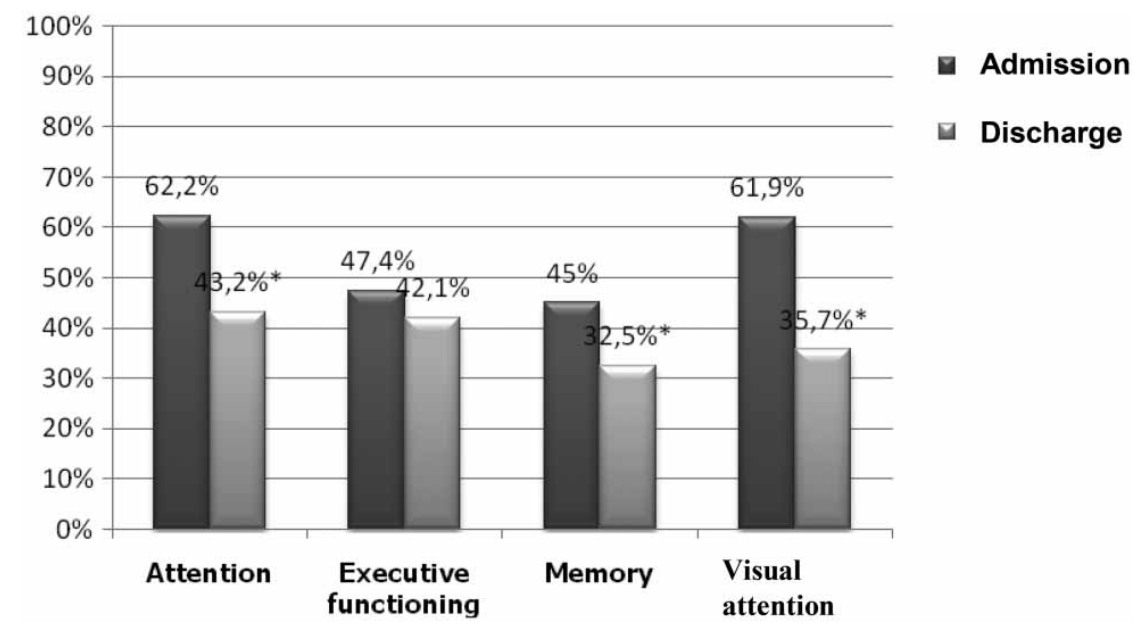

Figure 1. Percentages of cognitive impairments within a cognitive domain at admission and discharge. 
and discharge (35.7\% and $43.2 \%$, respectively). Significant recovery was found in the domains attention, memory and visual attention, but not in the domain of executive functioning. The largest improvement was seen in the domain of visual attention. This is illustrated in Figure 1.

\section{Factors influencing the course of cognition}

For the regression analysis, the VIF was always lower than 10 , and the average VIF was not higher then 1.

For recovery on all cognitive domains, age, location of stroke, level of education and cognitive rehabilitation were of no influence $(p>.05)$.

\section{DISCUSSION}

In this exploratory study we examined the course of cognitive functioning within the first months after stroke during rehabilitation. Most cognitive deficits were found in the domains of attention and visual attention, followed by executive functioning and memory. In all cognitive domains there were fewer deficits after rehabilitation compared to discharge. As such, we found that improvement occurs in all cognitive domains. In stroke literature more attention is given to cognitive deterioration and cognitive deficits than to cognitive recovery. In an earlier study on a stroke population admitted to the hospital, we found that up to $50 \%$ of the patients improved on cognitive functions within 6 months after stroke (Rasquin et al., 2004). This is comparable to other studies (Ballard, Rowan, Stephens, Kalaria, \& Kenny, 2003; Hofgren, Bjorkdahl, Esbjornsson, \& Stibrant-Sunnerhagen, 2006). A smaller, yet significant amount of improvement was reported by Desmond and colleagues within the same time-frame. They identified cognitive improvement in 10\% of the older stroke patients (mean age 70 years) examined (Desmond, Moroney, Sano, \& Stern, 1996). Another study with a slightly younger cohort (mean age 60 years) reported improvement of cognitive functioning in 30\% of the patients between 0 and 6 months and they could even be classified as cognitively intact by 12 to 18 months (Tham et al., 2002).

Recovery after stroke is mediated by both learning-dependent mechanisms (i.e., rehabilitation) and non-learning-dependent mechanisms (i.e., spontaneous neurobiological recovery) (Kwakkel, Kollen, \& Lindeman, 2004). Course of recovery after stroke is more thoroughly described in the field of language (course of aphasia) (Berthier \& Pulvermüller, 2011) and motor functioning (Wolfe et al., 2006) where it was shown that substantial improvement is seen when early and intensive training is offered to the patient. In these fields, improvement of functioning is linked to brain plasticity, but to avoid the confounding effect of spontaneous improvement, most trials are performed $>3$ months post-stroke (Johansson, 2011). In our study we also 
cannot discriminate between spontaneous recovery and recovery due to cognitive rehabilitation. We did perform analyses in which we examined the influence of cognitive rehabilitation on our results and we found no significant differences in the course of cognitive functioning between these groups. These results should, however, be interpreted with caution because many different forms and intensities of cognitive rehabilitation have been offered. In addition, two neuropsychological tests (TMT and TLT) can be influenced by practice effects. Nevertheless, these influences are only marginal (Mitchel \& Miller, 2008; Lemay et al., 2004). Moreover, we had no data on mood. It is possible that patients with depressive symptoms show less improvement.

Our study has some obvious limitations. We included patients from a rehabilitation centre. According to op Reimer, Scholte de Haan, Rijnders, Limburg, and van den Bos (1999) only $14 \%$ of all stroke patients who survive a stroke are admitted to a rehabilitation centre. This creates a selection bias, especially because improved functioning is one of the goals of rehabilitation. Moreover, cognitive deficits are, next to motor deficits, probably one of the main reasons for referral to a rehabilitation programme. However, in this specific patient population the largest amount of change can be expected, as such it is the most relevant group to investigate the course of cognitive functioning. A more elaborate neuropsychological assessment could give more insight into other relevant cognitive domains, such as mental speed. Also, a more elaborate neuropsychological assessment should include more tests for the same cognitive domain. Furthermore, we assessed only a small group of patients. Our sample included mostly patients with a right-sided stroke. However, stroke localisation was of no influence on the course of cognitive functioning. As such we hypothesise that a larger group would give comparable results.

There was a large variation in time between test occasions. However, post hoc analyses did not reveal a difference in cognitive performance for patients with short intervals compared to patients with longer intervals.

From a clinical point of view, it is important to be able to inform patients about the prognosis of their cognitive functioning. The current evidence, however, is still too limited for use in cognitive rehabilitation.

\section{REFERENCES}

Bailey, M. J., Riddoch, M. J., \& Crome, P. (2000). Evaluation of a test battery for hemineglect in elderly stroke patients for use by therapists in clinical practice. NeuroRehabilitation, 14, $139-150$.

Ballard, C., Rowan, E., Stephens, S., Kalaria, R., \& Kenny, R. (2003). Prospective follow-up study between 3 and 15 months after stroke: Improvements and decline in cognitive function among dementia-free stroke survivors $>75$. Stroke, 34, 2440-2444. 
Berthier, M. L., \& Pulvermüller, F. (2011). Neuroscience insights improve neurorehabilitation of poststroke aphasia. Nature Reviews Neurology, 7, 86-97.

Bots, M., \& van Dis, S. (2006). Cijfers en feiten Beroerte. Uitgave Nederlandse Hartstichting.

Christensen, B. K., Colella, B., Inness, E., Hebert, D., Monelle, G., Bayley, M., \& Green, R. (2008). Recovery of cognitive function after traumatic brain injury: A multilevel modelling analysis of Canadian outcomes. Archives of Physical Medicine and Rehabilitation, 89(2), S3-S15.

Delis, D., Kaplan, E., \& Kramer, J. (2001). D-KEFS examiner's manual. San Antonio, TX: The Psychological Corporation.

Desmond, D., Moroney, J., Sano, M., \& Stern, Y. (1996). Recovery of cognitive function after stroke. Stroke, 27, 1798-1803.

Folstein, M., Folstein, S., \& McHugh, P. (1975). "Mini-mental state". A practical method for grading the cognitive state of patients for the clinician. Journal of Psychiatric Research, 12(3), 189-198.

de Haan, R., Limburg, M., Schuling, J., Broeshart, J., Jonkers, L., \& Van Zuylen, P. (1993). Clinimetric evaluation of the Barthel-Index [in Dutch]. Nederlands Tijdschrift voor Geneeskunde, 37(18), 917-921.

van Heugten, C., Huygelen, K., \& van de Sande, P. (2004). Cognitive screening in stroke patients in rehabilitation: Standards for clinical practice [in Dutch]. Tijdschrift voor Gerontologie en Geriatrie, 35(5), 196-202.

Hochstenbach, J., Donders, A. R. T., Mulder, T. H., van Limbeek, J., \& Schoonderwaldt, H. (1996). The long-term outcome after stroke: A disability-oriented approach. International Journal of Rehabilitation Research, 19, 189-200.

Hofgren, C., Bjorkdahl, A., Esbjornsson, E., \& Stibrant-Sunnerhagen, K. (2006). Recovery after stroke: Cognition, ADL function and return to work. Acta Neurologica Scandinavica, 115, 73-80.

Johansson, B. B. (2011). Current trends in stroke rehabilitation. A review with focus on brain plasticity. Acta Neurologica Scandinavica, 123, 147-159.

Krikorian, R., Bartok, J., \& Gay, N. (1994). Tower of London procedure: Standard method and developmental data. Journal Of Clinical and Experimental Neuropsychology, 16(6), 840-850.

Kwakkel, G., Kollen, B., \& Lindeman, E. (2004). Understanding the pattern of functional recovery after stroke: Facts and theories. Restorative Neurology and Neuroscience, 22, 281-299.

Lemay, S., Bedard, M. A., Rouleau, I., \& Tremblay, P. L. (2004). Practice effect and test-retest reliability of attentional and executive tests in middle-aged to elderly subjects. Clinical Neuropsychologist, 18(2), 284-302.

Mitchel, M., \& Miller, L. S. (2008). Prediction of functional status in older adults: The ecological validity of four Delis-Kaplan Executive Function System tests. Journal of Clinical and Experimental Neuropsychology, 30(6), 683-690.

Nys, G., Van Zandvoort, M., De Kort, P., Van der Worp, H., Jansen, B., Kappelle, L., \& De Haan, E. H. (2005). Domain-specific cognitive recovery after first-ever stroke: A followup study of 111 cases. Journal of the International Neuropsychological Society, 11, 795-806.

Rasquin, S., Lodder, J., Ponds, R., Winkens, I., Jolles, J., \& Verhey, F. (2004). Cognitive functioning after stroke: A one-year follow-up study. Dementia and Geriatric Cognitive Disorders, 18, 138-144.

Rasquin, S., Ooms, N., Van de Sande, P., Beers, K., \& Schmand, B. (2009). Validity and data of reference of a visual-spatial search task: O-search-task [in Dutch]. Tijdschrift Voor Neuropsychologie. Diagnostiek, Behandeling En Onderzoek, 3, 44-54. 
op Reimer, W. J., Scholte de Haan, R. J., Rijnders, P. T., Limburg, M., \& van den Bos, G. A. (1999). Unmet care demands as perceived by stroke patients: Deficits in health care? Quality Health Care, 8(1), 30-35.

Reitan, R. (1956). Trail Making Test: Manual for administration, scoring, and interpretation. Bloomington: Indiana University.

Taesell, R., Bitensky, J., Salter, K., \& Bayona, N. A. (2005). The role of timing and intensity of rehabilitation therapies. Topics in Stroke Rehabilitation, 12(3), 47-59.

Tham, W., Auchus, A., Thong, M., Goh, M., Chang, H., Wong, M., \& Chen, C. (2002). Progression of cognitive impairment after stroke: One year results from a longitudinal study of Singaporean stroke patients. Journal of the Neurological Sciences, 203, 49-52.

Tham, K., \& Tegner, R. (1996). The Baking Tray Task: A test of spatial neglect. Neuropsychological Rehabilitation, 6(1), 19-25.

Van Balen, H., \& Groot Zwaaftink, A. (1987). The Rivermead Behavioural Memory Test. [Dutch translation]. Handleiding. Lisse: Swets \& Zeitlinger.

Verhage, F. (1964). Intelligence and age, research within the Dutch population, from 12 to 77 years of age (Dissertation). Assen: Van Gorcum.

Wade, D. T., \& Collin, C. (1998). The Barthel ADL index. A standard measure of disability? International Disability Studies, 10(2), 64-67.

Wagle, J., Farner, L., Flekkøy, K., Bruun Wyller, T., Sandvik, L., Fure, B., ... Engedal, K. (2011). Early post-stroke cognition in stroke rehabilitation patients predicts functional outcome at 1? months. Dementia and Geriatric Cognitive Disorders, 31(5), 379-387.

Wilson, B., Cockburn, J., \& Baddeley, A. D. (1985). The Rivermead Behavioural Memory Test. Tichfield: Thames Valley Test Company.

Wolfe, S. L., Winstein, C. J., Miller, J. P., Taub, E., Uswatte, G., Morris, D., . . Nichols-Larsen, D. (200?). Effect of constraint-induced movement therapy on upper extremity function 3 to 9 months after stroke: The EXCITE randomized clinical trial. Journal of the American Medical Association, 296, 2095-2104.

van der Zwaluw, C. S., Valentijn, S. A., Nieuwenhuis-Mark, R., Rasquin, S. M. C., \& van Heugten, C. M. (2011). Cognitive functioning in the acute phase poststroke: A predictor of discharge destination? Journal of Stroke and Cerebrovascular Disease, 20(6), 549-555. 